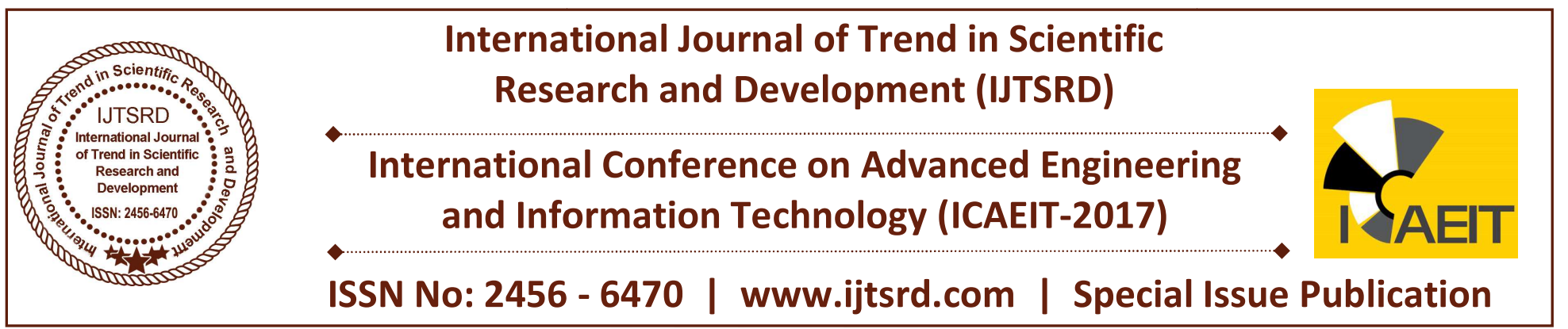

\title{
Outcome Based Education OBE Trend Review in Engineering Education
}

\author{
Deepak T $\mathbf{J}^{1}$, Venishri. $\mathbf{P}^{2}$ \\ ${ }^{1}$ Associate Professor, DEAN, Faculty of Engineering and Technology, Linton University College, \\ Mantin, Nilai, Malaysia \\ ${ }^{2}$ Manager - Quality Assurance Department, Linton University College, Mantin, Nilai, Malaysia
}

\section{ABSTRACT}

The reform in the Engineering that stresses on professionalism had brought the necessity to adopt outcome based education (OBE) in engineering education. It is an approach of education that clearly identifies its intended final product - students' competencies by determining the final curriculum outcome - a head of planning the framework of the curriculum. The explicit outcome is used to plan the curriculum, monitor its implementation, evaluate it and assess student's achievement. This paper is a review of the origin, benefits, drawbacks, and steps to implement outcome-based education. It is an attempt to provide a comprehensive coverage of a very popular current trend in engineering education

Keywords: Outcome-based education, Engineering education trends, curriculum planning.

\section{INTRODUCTION}

With contrary to the fact that most teachers put the center of their attention too much on what they teach rather than on what their students learn, OBE emphasizes on what is expected from the student to finally achieve when they complete their course rather than how they achieved it. Outcome based education is defined as an approach to education in which decisions about the curriculum are driven by the outcomes the students should display by the end of the course- professional knowledge, skills, abilities, values and attitudes- rather than on the educational process. It highlights the fact that you have to know the final destination of your travel before you start your journey $[1,2]$

\section{ORIGIN OF THE OUTCOME BASED EDUCATION}

OBE has been adopted for more than a century when educators brought to light the importance of appreciating students' individual variation in the learning process, believing that education is best measured by encouraging individual students' achievement that could occur at different rates for different students. OBE allows the students of different abilities to learn at their own rates with emphasis on programme outcome in professional engineering knowledge, skills and attitudes [3, 4].

OBE evaluation tool needs to integrate content delivery and assessment in order to evaluate the integration and holistic achievement on $\mathrm{CO}$ and PO by individual learners (Schuwirth\& Ash, 2013). An assessment tool design in $\mathrm{OBE}$ requires the instructional expert to define clear criteria by which the students output will be weighted and aligning with the assessed learning outcome. In another word, rubrics may provide the clear indication to the learner on what is expected of him/her to know or to do at the end of the learning outcome and how he/she will be assessed on the outcome attainment at $\mathrm{CO}$ level. Rubrics are essential for measuring outcomes which are complex and not easily quantifiable. A valid rubric is necessary to ensure a reliable measurement of the learning outcome. The validity of rubrics in measuring various characteristics of a specific outcome and the level descriptors of achievement is core of assessment transparency and fair grading practice.

Learning tools such as problem based learning, integrated design project, case studies, research based projects are some of the methods utilized to assess 
individual skills acquired by the students. The defined outcomes must be specific, measureable, achievable, realistic and time-based. All universities in Malaysia offering engineering degree programmes are now mandated by the Engineering Accreditation Council (EAC) to implement $\mathrm{OBE}$ as a requirement for accreditation. Linton University College in particular fully supports and implements OBE in its engineering programmes. In the field engineering education in Malaysia, Engineering Accreditation Council (EAC) plays a pivotal role in driving higher education providers to actively implement $\mathrm{OBE}$ as a prime criterion for accreditation. This effort is resonated by Board of Engineers Malaysia (BEM) as a requirement to be full member of Washington Accord. Guided by EAC Manual (2012) at Linton University College, all PEOs POs and COs have to be assessed under the OBE assessments strategy and CQI implementation has to be shown as an evidence for all engineering programmes according to the OBE model.

\section{NATURE OF THE OBE}

Outcome-based education approaches the curriculum decision making based on the competencies students should demonstrate at the end of each course and finally the program, thus the outcomes or competencies dictate the curriculum content and organization, the teaching methods and strategies, the course offered, the educational environment and the assessment strategies [8]. All curriculum and teaching decisions are made based on how best to facilitate the desired final outcome $[9,10]$.

\section{BENEFITS}

The adoption of OBE is perceived as a valuable addition to the engineering education process believing that with its clear specified outcomes it encourages participation and collaboration from multiple disciplines and interest groups in planning and implementing the curricula which will foster learning in various areas of engineering practice.

Educators believe that OBE does not only guaranty the clarity and assures the absence of controversy in curricula planning but also its relevance to the students' future practice. The clear, straightforward outcomes provided by OBE form a framework for decision - making and guidelines for assessment and program evaluation $[2,4]$.

The educators who support OBE in engineering education believe that the presence of specific, explicit outcomes, enables OBE to promote more selfdirected learning and allow students to have very good cognitive understanding of the educational program and their role in that process.

\section{DRAWBACKS}

The shift to OBE has attracted lots of opposition. Opponents believed that, education should be an open ended and should not be constrained by outcomes and that education should be valued for its own sake, not because it leads to some outcome. They believe that defining education as a set of outcomes - decided in advance of teaching and learning - conflicts with the wonderful, unpredictable voyages of exploration that characterize learning through discovery and inquiry. They mistakenly assume that teaching will be inappropriately limited by this model [4, 14].

Critics of OBE, object to the use of standardized tests thinking that it is partial to use the same level of work or to use the same achievement tests for disadvantaged or underprivileged students as they do for more advantaged students.

\section{STEPS IN IMPLEMENTING OBE}

For successful implementation of OBE system, the following parameters are to be defined clearly with help of feedback from industrial and professional bodies.

\section{A. Institutional Requirements}

$>$ Strong vision and mission statement of the institution stating the core values, business values and ethical values.

$>$ Vision and mission statement must commendable and entrust the stakeholders as well as learning committee.

\section{B. Programme Requirements}

$>$ With feedbacks from industrial and professional bodies to develop the curriculum for the particular course

$>$ Developing programme Educatonal Objectives (PEO) and Programme outcomes (PO).

$>$ Mapping PEO to $\mathrm{PO}$ and with institutions vision and mission

\section{Course outcomes}

$>$ Refining curriculum with determining the order of courses and defining the prerequisite for each courses.

Developing course outcomes(CO) for each course, 
Setting a threshold for assessment for courses for determining course outcome attainment.

\section{Assessment}

Cleary describing the results to be measured.

$>$ Classifying the data and resources availability and applying assessment related to the course

Each assessment must have a strong rubric which can denote how marks can be achieved

\section{CONCLUSION}

OBE is a new educational approach considered in planning, implementing and evaluation of curricula. It promises high level of learning for all students based on the achievement of clearly explicit outcomes with concern to the relevance of each learner's development level and promising active and experienced-based learning. It provides the learner with the destination of the educational journey before the journey is performed.

\section{REFERENCES}

1. Harden, R.M., Davis, M.H. \& Crosby, J.R. (1997). The new Dundee medical curriculum: a whole that is greater than the sum of the parts, Medical Education, 31, 264-271.

2. McNeil P H., Hughes CS, Toohey SM \& Dowton SB (2006). An innovative outcomes-based medical education, program built on adult learning principles. Medical Teacher, Vol. 28, No. 6,. 527534

3. Harden, R.M. (2002a) Developments in outcomebased education, Medical Teacher, 24, 117-120.

4. Harden, R.M., Crosby, J.R. \& Davis, M.H. (1999). AMEE Guide No. 14: Outcome-based education: Part 1-an introduction to outcome based education, Medical Teacher, 21, 7-14.

5. Schwartz, M.R. \&Wojtczak, A. (2002) Global minimum essential requirements: a road towards competence-oriented medical education, Medical Teacher, 24, 125-129.
6. Australian Medical Council (2002) Assessment and Accreditation of Medical Schools: Standards and Procedures, AMC, Canberra).

7. Simpson, J.G., Furnance, J., Crosby, J., Cummings, A.D., Evans, P.A., Friedman, M., et al. (2002) The Scottish doctor-learning outcomes for the medical undergraduate in Scotland: a foundation for competent and reflective practitioners, Medical Teacher, 24, 136-143.

8. Harden, R.M. (1986). Ten questions to ask when planning a course or curriculum. ASME Medical Education booklet no 20, Medical Education, 20, 356-365.

9. Spady, W. (1988). Organizing for results: the basis of authentic restructuring and reform. Educational Leadership. Vol. 46, No. 2 4- 8.

10. Spady, W. (1993).Outcome-based Education. Belconnen, ACT: Australian Curriculum Studies Association.

11. Accreditation Council on Graduate Medical Education (ACGME) (2001) ACGME outcome project Available: http://www. acgme.o rg/outcome/comp/compFull.asp

12. Harden R.M. and Dent J .A. (2005). A Practical Guide for Medical Teachers .2nd edition, Elsevier Churchill Livingstone ISBN 044310083 ch.14,pp.124-133

13. Willis, S. and Kissane, B. (1995). Systemic Approaches to Articulating and Monitoring Expected Student Outcomes. Murdoch, Western Australia: Murdoch University.

14. Mckernan, J. (1993) Perspectives and imperatives: some limitations of outcome-based education, Journal of Cur $\mathrm{r}$ iculum and Supervision, 8(4), 343-353.

15. Towers, J.M. (1996). 'An elementary school principal's experience with implementing an outcome-based curriculum'. Catalyst for Change. Vol. 25, 19-23. 